Article

\title{
Growth, Yield, and Water Productivity Responses of Pepper to Sub-Irrigated Planter Systems in a Greenhouse
}

\author{
Marjan Vahabi Mashhor ${ }^{1}$, Mahmoud Mashal ${ }^{1}$, Seyyed Ebrahim Hashemi Garmdareh ${ }^{1, *}{ }^{(\mathbb{C}}$, \\ Juan Reca $^{2}$, Maria Teresa Lao ${ }^{3, *(\mathbb{D})}$, Maryam Veravipour ${ }^{1}$ and Hamed Ebrahimian ${ }^{4}(\mathbb{D}$ \\ 1 Department of Irrigation and Drainage Engineering, College of Aburaihan, University of Tehran, \\ Tehran 1417466191, Iran; Marjan.vahabi@ut.ac.ir (M.V.M.); mmashal@ut.ac.ir (M.M.); mvaravi@ut.ac.ir (M.V.) \\ 2 Department of Engineering, University of Almeria, 04120 Almeria, Spain; jreca@ual.es \\ 3 Department of Agronomy, University of Almeria, 04120 Almeria, Spain \\ 4 Department of Irrigation and Reclamation Engineering, College of Agricultural and Natural Resources, \\ University of Tehran, Karaj 3158777871, Iran; ebrahimian@ut.ac.ir \\ * Correspondence: mtlao@ual.es (M.T.L.); sehashemi@ut.ac.ir (S.E.H.G.)
}

Received: 15 January 2020; Accepted: 1 February 2020; Published: 4 February 2020

check for updates

\begin{abstract}
A sub-irrigated planter (SIP) is a container irrigation technique in which water is supplied to the crop from the bottom, stored in a saturated media-filled reservoir beneath an unsaturated soil, and then delivered by capillary action to the root zone. The aim of this study was to optimize the water management and to assess the performance of this technique in terms of water use efficiency, soil moisture, and solute distribution in comparison with surface irrigation in a Mediterranean greenhouse. The experiment consisted of four SIP treatments, with a constant water level in the bottom reservoir in order to evaluate the effect of two different irrigation salinities $\left(1.2\right.$ and $\left.2.2 \mathrm{dS} \mathrm{m}^{-1}\right)$ and two depths of substrate profiles ( 25 and $15 \mathrm{~cm}$ ). The results showed that SIP is capable of significantly improving both water-use efficiency and plant productivity compared with surface irrigation. Also, a $24 \%$ average reduction in water consumption was observed while using SIP. Moreover, SIPs with a higher depth were recommended as the optimum treatments within SIPs. The type of irrigation method affected the salinity distribution in the substrate profile; the highest salinity levels were registered at the top layers in SIPs, whereas the maximum salinity levels for the surface treatments were observed at the bottom layers. SIPs provide a practical solution for the irrigation of plants in areas facing water quality and scarcity problems.
\end{abstract}

Keywords: sub-irrigated planter; Capsicum annuum L.; capillary; water use efficiency; plant productivity; salinity

\section{Introduction}

In terms of addressing the global water shortage in agriculture, which accounts for $70 \%$ of global freshwater withdrawals [1], subsurface irrigation currently represents the most efficient irrigation technique in providing water to plants [2,3]. In subsurface irrigation, water is supplied by creating and maintaining a reservoir below the ground surface. Moisture moves upwards through capillary action, in order to meet the water requirements of the crop. As the water is supplied below the surface, water evaporation is negligible in this method, and thus more water is available for the plant's roots [4]. 
In recent years, larger portions of the world's agricultural production have adopted "sub-irrigated container" systems [5] in order to improve on the efficiency of traditional in-ground subsurface systems, and to address climate change, water shortage, and saline water resources [6]. These techniques consist of producing ornamental and agricultural crops in pots using subsurface irrigation systems [7]. Containerized planting helps reduce water consumption more than in-ground subsurface systems, as it maintains the water in the soil profile in the pot. In addition, in this method, soil contamination issues are solved [8]. There are also different types of sub-irrigated containerized planting, such as capillary wick, negative pressure, hydroponic methods (kratky, ebb and flow, etc.), and wicking mats, which have been studied in literature all around the world, and have obtained promising results. Studies have reported that ornamentals showed a better marketability, leaf expansion, and plant height when capillary wick irrigation was utilized compared with surface irrigation. Furthermore, water usage dropped by $63 \%$ when using capillary wick irrigation [9]. It also has been found that the hotness of the hot pepper plant increased using the negative pressure capillary irrigation technique, in comparison with surface irrigation, and water consumption was reduced by $35 \%$. Consequently, the negative pressure technique offers precise water delivery, which can be suitable for greenhouse planting in areas with a limited water supply [10].

The current research is focused on a simple and practical type of container irrigation method called "sub-irrigated planter" (SIP) or self-watering pot. SIP systems have been popular in both urban agriculture [11,12] and large-scale agriculture throughout the entire growing season [8], as they do not require high installation and maintenance costs, but have displayed promising results. SIP consists of a saturated media-filled reservoir beneath an unsaturated soil (root zone) and water is delivered by capillary action to the root zone in response to the water requirement of the plant [13]. Thus, this simple method seems to meet all of the efficiency requirements mentioned above; both reducing drainage and soil contamination and decreasing water utilization by eliminating water evaporation. Moreover, according to the Food and Agriculture Organisation of the United Nations (FAO) 48 [14], waters of much higher salinity can be used effectively for the production of selected crops under the right conditions; therefore, the effect of saline water on SIP performance was studied as a part of the present study for the first time in the literature. Also, there is limited information regarding the distribution of moisture and salt within soilless media during containerized crop production methods such as SIP. Hence, not only is it important to analyze the growing medium behavior and plant production during the growing season while using SIP, but it is also necessary to establish some guidelines about water quality and medium depth.

The province of Almería in the southeast of Spain, where this study was conducted, is one of the most extended horticultural greenhouses areas in the world, with more than 30,000 hectares of greenhouses devoted to the production of vegetables. Pepper (Capsicum annuum L.) is the second most important crop in Almería after tomato, both in terms of cropped area and total production [15]. It is a plant with a high sensitivity to salinity. According to the Maas and Hoffman model [16], its saturated extract electrical conductivity $\left(E_{\mathrm{e}}\right)$ threshold value is $1.5 \mathrm{dS} \mathrm{m}^{-1}$ with a slope of 14 . Other researchers [17] have reported that the soil salinity level was linearly related to the reduction of the total yield of pepper grown in the substrate, even under moderate salinity levels. Salinity not only affects crop yield, but also other physiological processes, such as root cellular turgor, net $\mathrm{CO}_{2}$ assimilation rates, photosynthesis, stomatal conductance, and transpiration, among others [18-20]. Pepper was thus selected as an appropriate experimental crop because of its economic importance and its sensitivity to salinity.

The key objectives of this study were to provide the aforementioned details about SIPs by applying two qualities of irrigation water at two soil depths in pots where pepper was planted. This process evaluated the following: (1) the effect of water salinity on SIP efficiency, (2) the effect of soil depth on SIP efficiency, (3) water-use efficiency and plant productivity in SIP compared with surface irrigation, and (4) the distribution of moisture and salt in the soil profile. Ultimately, the study provided suggestions for the optimum soil depth and water quality to be used in SIP for pepper. 


\section{Materials and Methods}

\subsection{Study Site}

The present study was carried out in a $150 \mathrm{~m}^{2}$ tunnel greenhouse with a ventilation system and relative humidity and temperature control, located at the University of Almeria $\left(36^{\circ} 49^{\prime} \mathrm{N}, 2^{\circ} 24^{\prime} \mathrm{W}\right)$, Almeria, Spain.

Almeria presents a Mediterranean semi-arid climate, with an average annual rainfall of $260 \mathrm{~mm}$ and a wide dry period during the summer months. The average monthly temperatures range from $11.8^{\circ} \mathrm{C}$ in January to $26^{\circ} \mathrm{C}$ in July [21].

Temperature, relative humidity, and solar radiation data were collected using a HOBO U30 weather station (Onset Computer Corporation, Bourne, MA, USA) installed inside the greenhouse for the entire growing season. The data were downloaded and processed using the HOBOware program (Onset Computer Corporation, Bourne, MA, USA).

\subsection{Treatments Details}

The experimental design was a split-split plot and plot, with three factors $(2 \times 2 \times 2$, namely: irrigation technique, depth of growing medium, and water irrigation salt level, respectively) and a total of eight treatments, three randomized complete repetitions, and four plants per pot and per block, giving the plus border plants a total of 128 plants. The combinations of tested factors of the experiment are depicted in Figure 1. The irrigation techniques essayed were the sub-irrigated planter (SIP) and surface irrigation $(\mathrm{O})$. The depth of the growing medium essayed were $25\left(\mathrm{D}_{1}\right)$ and $15 \mathrm{~cm}\left(\mathrm{D}_{2}\right)$. The qualities of water essayed were $1.2\left(\mathrm{~S}_{1}\right)$ and $2.2 \mathrm{dS} \mathrm{m}^{-1}\left(\mathrm{~S}_{2}\right)$. Statistical analysis was performed using the SPSS version 16.0 statistical software (SPSS Inc, Chicago, IL, USA). A probability of $p<0.05$ was considered significant.

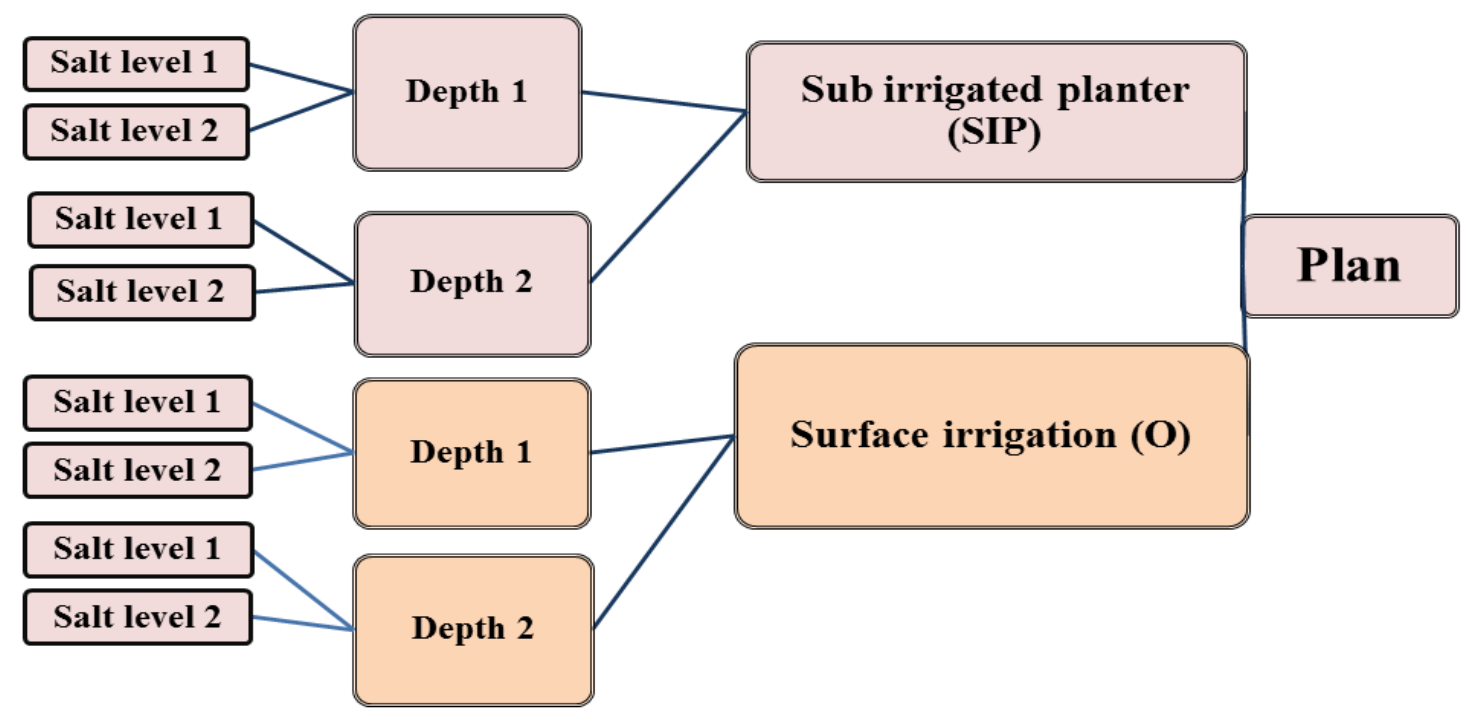

Figure 1. Treatments details: sub-irrigated planter (SIP) and surface irrigation $(\mathrm{O})$; depth $1\left(\mathrm{D}_{1}\right)=25 \mathrm{~cm}$; depth $2\left(\mathrm{D}_{2}\right)=15 \mathrm{~cm}$; salt level $1\left(\mathrm{~S}_{1}\right)=1.2 \mathrm{dS} \mathrm{m} \mathrm{m}^{-1}$, salt level $2\left(\mathrm{~S}_{2}\right)=2.2 \mathrm{dS} \mathrm{m}^{-1}$. 


\subsection{Planters and Plant Details}

Pepper (Capsicum annuum) was planted in an experimental greenhouse at the University of Almeria for a growing season lasting from June to September 2019. The seedlings were purchased from a local nursery and were ready to be transplanted into pots. The pots presented holes on the bottom and measured $30 \mathrm{~cm}$ in diameter and $30 \mathrm{~cm}$ in height $(21.2 \mathrm{~L})$. Half of the pots were used for surface irrigation $(\mathrm{O})$ and half of them for sub-irrigated planter (SIP). The surface pots were filled only with a growing medium, which was controlled by the weight. In order to construct the SIP systems, the pots were divided into two parts, namely: reservoir below and unsaturated growing media above (Figure 2). A layer of gravel was used at the bottom of each SIP pot as a reservoir $(1.5 \mathrm{~cm}$ gravel layer for deeper depth and $1 \mathrm{~cm}$ layer for the lower growing medium depth), the use of gravel in reservoirs creates a medium that is porous and permeable so that it both holds a substantial volume of water and can be quickly filled.

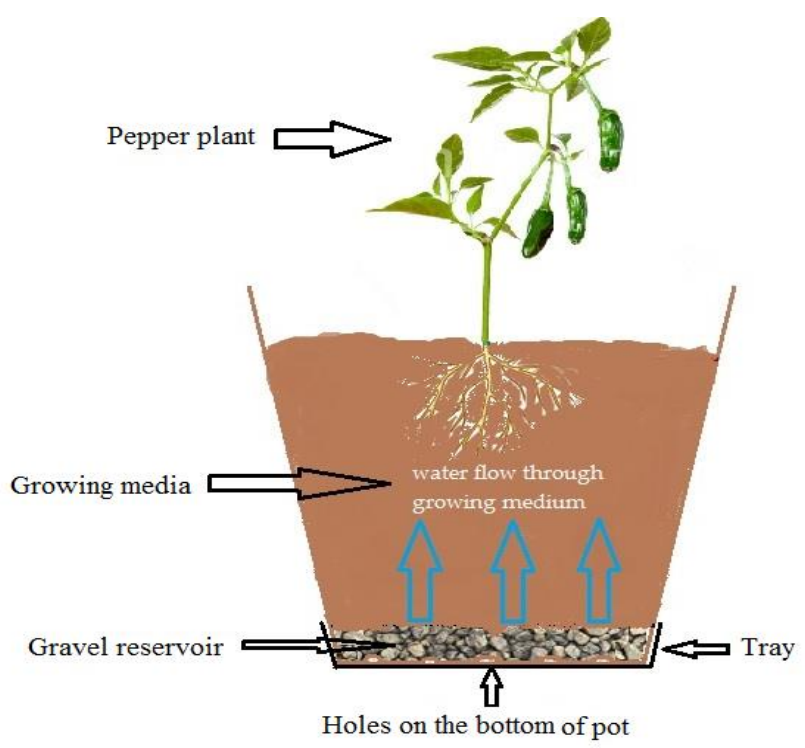

Figure 2. SIP system scheme.

\subsection{Growing Medium Details}

The growing media used was a mixture of cocopeat and perlite 3:1 v/v [22,23]. Growers typically utilize this soilless mixture in greenhouses for two main reasons, namely: (1) using lower bulk density materials allows for containers to be easily relocated [24], and (2) ample airspace is provided to ensure adequate gas exchange and to minimize the risk of diseases. The bulk density, particle density, and total porosity values were $0.13,0.47 \mathrm{~g} \mathrm{~cm}^{-3}$, and $72 \%$, respectively, for the soilless growing medium.

\subsection{Irrigation, Leaching, and Fertilizing Scheduling}

After transplanting, all of the plants received surface irrigation for one week to help plant growth. Then, the irrigation scheduling was applied. Under the SIP system, the water level was kept constant by trays placed below each pot and the surface of this tray was completely covered so as to avoid evaporation. The water in the trays moves through the holes at the bottom of the pot to the gravel reservoir and rises by capillary action to the substrate. The level of water was maintained at 1.5 and 1 $\mathrm{cm}$ in the gravel layer throughout the entire growing season by adding water to the trays daily and recording the volume applied. This volume was considered the water absorbed by plants per pot, because SIP systems are closed. The water was applied manually under surface irrigation. The daily volume applied was the same volume applied in the SIP plus the volume corresponding to free drainage of the pot. 
Considering that the pepper salinity tolerance level is $1 \mathrm{dS} \mathrm{m}^{-1}$ for irrigation water salinity [19-21], two qualities of water were obtained by the addition of $\mathrm{NaCl}$ to water irrigation (Table 1) to rise the Electrical Conductivity (EC) of 1.2 and $2.2 \mathrm{dS} \mathrm{m}^{-1}$. Also, a nutrient solution (Table 1) was applied fortnightly at a rate of $70 \mathrm{~mL}$ per plant in both irrigation systems, to allow for a more efficient use of both water and fertilizers [22,23].

Table 1. Water and nutrient solution characterization.

\begin{tabular}{|c|c|c|c|c|c|c|c|c|c|c|}
\hline \multirow{2}{*}{\multicolumn{2}{|c|}{$\mathrm{EC}\left(\mathrm{dS} \mathrm{m}^{-1}\right)$}} & \multirow{2}{*}{ pH } & \multicolumn{8}{|c|}{ Macro-Nutrients (mmol L $\mathrm{L}^{-1}$ ) } \\
\hline & & & $\mathrm{NO}_{3}{ }^{-}$ & $\mathrm{H}_{2} \mathrm{PO}_{4}{ }^{2-}$ & $\mathrm{SO}_{4}^{2-}$ & $\mathrm{Cl}^{-}$ & $\mathrm{K}^{+}$ & $\mathrm{Ca}^{2+}$ & $\mathrm{Mg}^{2+}$ & $\mathrm{Na}^{+}$ \\
\hline Water & 0.9 & 7.8 & & & 1.1 & 3.5 & & 2.0 & 1.4 & 2.6 \\
\hline N. Solution & 1.5 & 6.5 & 6.0 & 0.7 & 2.0 & 3.5 & 3.0 & 2.0 & 1.4 & 2.6 \\
\hline
\end{tabular}

\subsection{Crop and Potential Evapotranspiration}

Reference evapotranspiration was calculated using the Penman-Monteith equation as a function of the registered climatic variables. Crop evapotranspiration was calculated by applying a daily water balance equation to each pot (See Equation (1)).

$$
E T_{c}=V_{I}-V_{D} \pm \Delta V_{S}
$$

where: $E T_{c}=$ crop evapotranspiration, $V_{I}=$ is the daily irrigation water applied, $V_{D}=$ is the irrigation water drained and $\Delta V_{S}$ is the variation of the water content in the substrate. For SIP pots $V_{D}$ was equal to zero and $\Delta V_{S}$ was neglected in a daily basis.

\subsection{Water Use Efficiency, Moisture, and Solute Distributions}

Water use efficiency, defined as the irrigation water volume required to produce a given total mass of yield, was estimated and compared for all of the treatments at the end of the growing season. All of the planters were divided into $5 \mathrm{~cm}$ layers, and the volumetric moisture contents and salinity levels of these $5 \mathrm{~cm}$ growing medium layers were measured and monitored throughout the season. The volumetric moisture content was measured by the gravimetric method; the salinity levels were measured by collecting the growing medium water extract and then measuring the salinities using an EC-meter.

\section{Results}

\subsection{Greenhouse Meteorological Data}

The meteorological data inside the greenhouse effect plant growth. Thus, it is essential to gather such data in order to measure the potential evapotranspiration and crop coefficient. Figure 3 illustrates the meteorological data, including temperature, relative humidity, and solar radiation over the course of the research period. The temperature and relative humidity ranged from 30.9 to $32.2{ }^{\circ} \mathrm{C}$ and $88 \%$ to $98 \%$, respectively. The peak solar radiation was reached in August.

\subsection{Plant Productivity and Water Use Efficiency (WUE)}

The growth of the pepper plants used in this study was assessed in terms of dry and fresh yield weights, height of plants' canopy, and number of leaves (Table 2). All of these growth parameters were noticeably different between the sub-irrigated planter and surface treatments. The values of these parameters were considerably lower in the surface irrigation than in the SIP. Within the SIP treatment; the most significant factor affecting the growth of the crop was the depth of the substrate profile, whereas the irrigation water salinity level did not affect the growth parameters (Tukey's test, $p<0.05)$. The results are shown in Table 2 . 


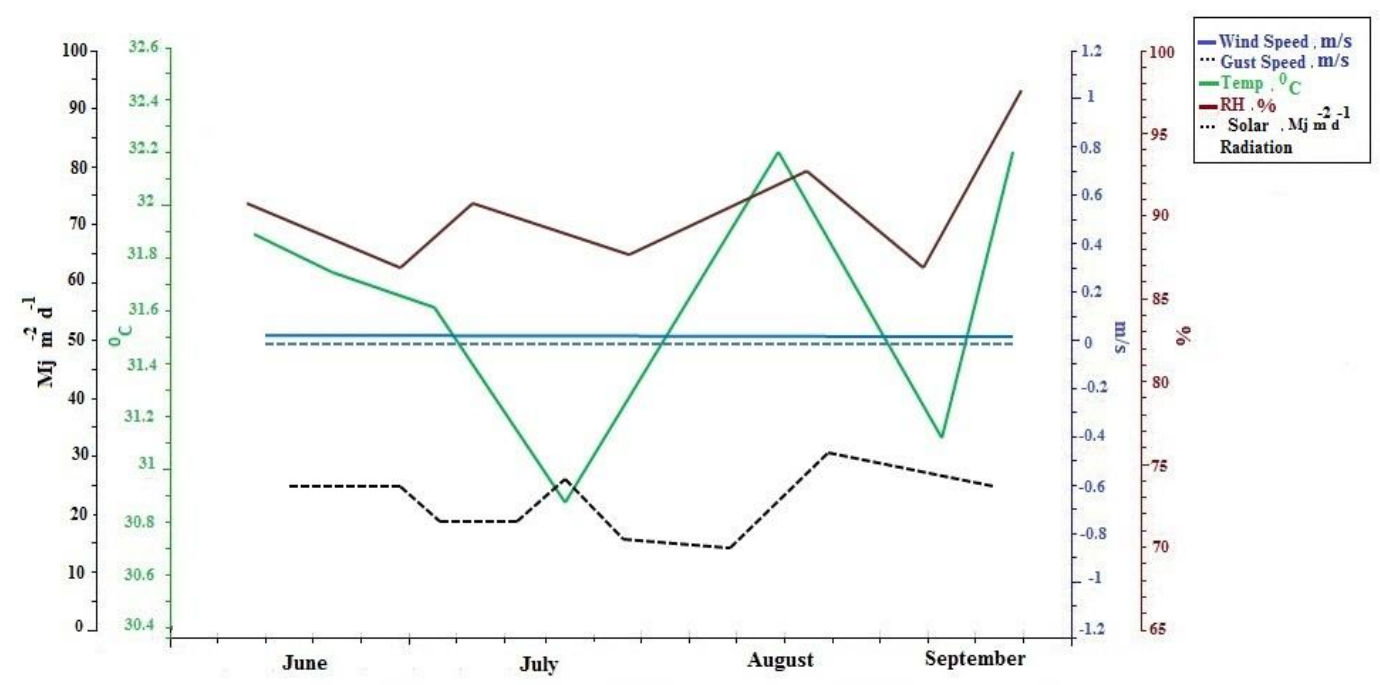

Figure 3. Meteorological data inside the greenhouse over the course of the growth period.

Table 2. Growth parameters, total irrigation, and water-use efficiency of pepper plants subjected to different irrigation treatments.

\begin{tabular}{|c|c|c|c|c|c|c|}
\hline Treatment & $\begin{array}{l}\text { Total Fresh } \\
\text { Yield } \\
\text { (g plant }^{-1} \text { ) }\end{array}$ & $\begin{array}{l}\text { Total Dry } \\
\text { Yield } \\
\text { (g plant }^{-1} \text { ) }\end{array}$ & $\begin{array}{l}\text { Height of Plant } \\
\text { Canopy }(\mathrm{cm})\end{array}$ & $\begin{array}{l}\text { Number of } \\
\text { Leaves }\end{array}$ & $\begin{array}{c}\text { Total } \\
\text { Irrigation } \\
\left.\text { (L plant }^{-1}\right)\end{array}$ & WUE $\left(\mathrm{g} \mathrm{L}^{-1}\right)$ \\
\hline SIP-S ${ }_{1}-D_{1}$ & $57.47 \pm 0.78 \mathrm{a}$ & $9.50 \pm 0.61 a$ & $66.33 \pm 0.44 a$ & $42.33 \pm 0.33 a$ & $12.72 \pm 0.21 b$ & $4.52 \pm 0.11 a$ \\
\hline SIP-S ${ }_{1}-D_{2}$ & $44.45 \pm 0.35 b$ & $5.06 \pm 0.04 b$ & $60.00 \pm 0.58 b$ & $36.33 \pm 1.33 b$ & $8.92 \pm 0.22 c$ & $4.99 \pm 0.10 \mathrm{a}$ \\
\hline SIP-S $-D_{1}$ & $55.79 \pm 0.85 a$ & $8.80 \pm 0.69 a$ & $66.00 \pm 0.58 a$ & $41.67 \pm 0.67 a$ & $12.29 \pm 0.11 b$ & $4.54 \pm 0.10 \mathrm{a}$ \\
\hline SIP-S $-D_{2}$ & $42.91 \pm 0.26 b$ & $5.14 \pm 0.04 b$ & $59.90 \pm 0.158 b$ & $35.67 \pm 0.88 b$ & $8.83 \pm 0.26 c$ & $4.87 \pm 0.16 \mathrm{a}$ \\
\hline $\mathrm{O}-\mathrm{S}_{1}-\mathrm{D}_{1}$ & $41.15 \pm 1.28 b$ & $5.59 \pm 0.58 b$ & $59.67 \pm 0.67 b$ & $33.00 \pm 0.58 b c$ & $15.75 \pm 0.05 a$ & $2.61 \pm 0.09 b$ \\
\hline $\mathrm{O}-\mathrm{S}_{1}-\mathrm{D}_{2}$ & $34.07 \pm 0.94 \mathrm{c}$ & $3.84 \pm 0.17 \mathrm{~b}$ & $53.00 \pm 0.58 c$ & $29.00 \pm 0.58 \mathrm{~cd}$ & $12.50 \pm 0.09 b$ & $2.73 \pm 0.08 b$ \\
\hline $\mathrm{O}-\mathrm{S}_{2}-\mathrm{D}_{1}$ & $36.07 \pm 1.55 c$ & $4.96 \pm 0.33 b$ & $53.07 \pm 1.16 c$ & $26.67 \pm 1.67 \mathrm{de}$ & $15.60 \pm 0.08 a$ & $2.31 \pm 0.10 b$ \\
\hline $\mathrm{O}-\mathrm{S}_{2}-\mathrm{D}_{2}$ & $32.59 \pm 0.46 c$ & $3.77 \pm 0.18 b$ & $49.47 \pm 0.32 \mathrm{~d}$ & $23.33 \pm 0.88 \mathrm{e}$ & $12.23 \pm 0.32 b$ & $2.67 \pm 0.10 b$ \\
\hline
\end{tabular}

Note: Letters in each column indicate significant differences (Tukey's test, $p<0.05$ ). WUE-water use efficiency.

The total irrigation during the growing season was higher in the treatments with a higher substrate depth than in those with a lower depth. While such an observation is reasonably to be expected, the most notable finding in the trial was the substantial reduction in the total irrigation figures when using SIPs; $19 \%, 28 \%, 21 \%$, and $27 \%$ total irrigation declines were observed in SIPs compared with surface treatments, respectively (Table 2).

SIPs had the highest water use efficiency figures in all of the treatments compared with the surface treatments. The maximum WUE value was seen in SIP-S1-D2, reaching $4.99 \mathrm{gr} \mathrm{L}^{-1}$, which was 1.83 times higher than O-S1-D2. This SIP treatment also had the maximum WUE among all SIPs, although the figures showed no significant difference in $p<0.05$ within the SIP treatments.

Table 3 shows the effect of irrigation treatment on plant canopy (stem and leaves) and root systems. According to this table, the SIP significantly increased the root and canopy weights compared with surface irrigation. To compare the SIP treatments, Table 3 showed that water salinity levels did not affect the canopy and root weights between the SIP-S1 and SIP-S2 treatments; although the depth caused a remarkable difference and the SIP-D1 treatments experienced considerably greater fresh root weights than SIP-D2s. The canopies also had noticeably greater weight values in the SIP than the surface treatments; although they did not differ significantly among SIPs. Fresh canopy/root ratios did not substantially differ among all of the treatments; except for figures in O-S1-D2 and O-S2-D2 treatments, which were far higher than the SIPs. 
Table 3. Comparison between the canopy and root systems of pepper plants subjected to different irrigation treatments.

\begin{tabular}{|c|c|c|c|c|c|c|}
\hline Treatment & Fresh Root (g) & Dry Root (g) & $\begin{array}{c}\text { Fresh Canopy } \\
\text { (g) }\end{array}$ & $\begin{array}{l}\text { Dry Canopy } \\
\text { (g) }\end{array}$ & $\begin{array}{c}\text { Fresh } \\
\text { Canopy/Root } \\
\text { Ratio }\end{array}$ & $\begin{array}{c}\text { Dry } \\
\text { Canopy/Root } \\
\text { Ratio }\end{array}$ \\
\hline SIP-S ${ }_{1}-D_{1}$ & $6.28 \pm 0.15 a$ & $0.52 \pm 0.01 \mathrm{a}$ & $79.85 \pm 2.28 \mathrm{a}$ & $8.87 \pm 0.59 \mathrm{ab}$ & $12.71 \pm 0.18 c$ & $17.04 \pm 0.84 b$ \\
\hline SIP-S $-D_{2}$ & $4.73 \pm 0.25 b$ & $0.40 \pm 0.00 \mathrm{ab}$ & $72.77 \pm 1.26 \mathrm{ab}$ & $7.30 \pm 0.41 b c$ & $15.46 \pm 0.75 c$ & $18.10 \pm 1.03 b$ \\
\hline SIP-S ${ }_{2}-D_{1}$ & $5.93 \pm 0.23 a$ & $0.51 \pm 0.02 \mathrm{a}$ & $81.57 \pm 1.08 \mathrm{a}$ & $9.36 \pm 0.28 a$ & $13.80 \pm 0.59 c$ & $18.40 \pm 0.95 b$ \\
\hline SIP-S $-\mathrm{D}_{2}$ & $4.58 \pm 0.32 b c$ & $0.41 \pm 0.03 \mathrm{ab}$ & $75.20 \pm 2.61 \mathrm{a}$ & $8.09 \pm 0.49 \mathrm{ab}$ & $16.55 \pm 0.97 b c$ & $19.99 \pm 0.49 b$ \\
\hline $\mathrm{O}-\mathrm{S}_{1}-\mathrm{D}_{1}$ & $3.96 \pm 0.18 b c$ & $0.38 \pm 0.05 a b$ & $62.50 \pm 3.18 b c$ & $5.76 \pm 0.37 \mathrm{~cd}$ & $15.91 \pm 1.51 c$ & $15.73 \pm 2.59 b$ \\
\hline $\mathrm{O}-\mathrm{S}_{1}-\mathrm{D}_{2}$ & $2.58 \pm 0.05 d$ & $0.13 \pm 0.03 c$ & $53.67 \pm 2.73 c$ & $4.83 \pm 0.26 \mathrm{~d}$ & $20.82 \pm 1.17 \mathrm{ab}$ & $32.30 \pm 5.58 \mathrm{ab}$ \\
\hline $\mathrm{O}-\mathrm{S}_{2}-\mathrm{D}_{1}$ & $3.77 \pm 0.13 c$ & $0.28 \pm 0.04 b$ & $64.23 \pm 1.89 b c$ & $5.09 \pm 0.49 d$ & $17.08 \pm 0.83 b c$ & $22.38 \pm 3.90 b$ \\
\hline $\mathrm{O}-\mathrm{S}_{2}-\mathrm{D}_{2}$ & $2.24 \pm 0.12 \mathrm{~d}$ & $0.12 \pm 0.02 c$ & $55.42 \pm 1.42 c$ & $4.60 \pm 0.25 d$ & $24.83 \pm 0.84 \mathrm{a}$ & $41.13 \pm 6.30 \mathrm{a}$ \\
\hline
\end{tabular}

Note: Letters in each column indicate significant differences (Tukey's test, $p<0.05$ ).

\subsection{The Culture Evapotranspiration (ETc) and Reference Evapotranspiration (ETo) Data}

Table 4 presents a summary of the actual evapotranspiration measurements taken at the initial, developing, middle, and late stages of the study, as well as the estimated $\left(\mathrm{ET}_{0}\right)$ and crop coefficient $(\mathrm{Kc})$ values for pepper over the course of the growth period. ETc reached its highest level in the SIP-S1-D1 treatment during the middle stage. At the initial stage, the ETc figures (and Kc values logically), did not differ significantly between the SIP and surface treatments. At the developing stage, the results were also the same between the SIP and surface treatments; whereas among the SIPs, the figures were higher in SIPs-D1 compared with SIPs-D2. At the middle stage, only the ETc values for SIP-S2-D2 and O-S2-D2 differed considerably. Finally, the ETc figures were far higher in SIP-S1-D1 than O-S1-D1, and in O-S1-D2 than SIP-S1-D2 at the late growth stage.

Table 4. Crop evapotranspiration and Kc values for four growth stages, namely: initial, developing, middle, and late stages.

\begin{tabular}{|c|c|c|c|c|c|c|c|c|c|c|c|c|}
\hline \multirow{2}{*}{ Treatment } & \multicolumn{3}{|c|}{ Initial } & \multicolumn{3}{|c|}{ Developing } & \multicolumn{3}{|c|}{ Middle } & \multicolumn{3}{|c|}{ Late } \\
\hline & ETc & $\mathrm{ET}_{0}$ & Kc & ETc & $\mathrm{ET}_{0}$ & Kc & ETc & $\mathrm{ET}_{0}$ & Kc & ETc & $\mathrm{ET}_{0}$ & Kc \\
\hline SIP-S ${ }_{1}-D_{1}$ & $1.58 \pm 0.11 \mathrm{abc}$ & 2.19 & 0.72 & $1.82 \pm 0.05 a$ & 1.6 & 1.13 & $2.11 \pm 0.03 a$ & 1.75 & 1.21 & $1.98 \pm 0.04 a$ & 1.77 & 1.12 \\
\hline SIP-S $-D_{2}$ & $1.20 \pm 0.05 c$ & 2.19 & 0.55 & $1.43 \pm 0.05 c$ & 1.6 & 0.9 & $1.42 \pm 0.09 \mathrm{~d}$ & 1.75 & 0.8 & $1.18 \pm 0.04 \mathrm{e}$ & 1.77 & 0.67 \\
\hline SIP-S $-D_{1}$ & $1.73 \pm 0.17 a b c$ & 2.19 & 0.8 & $1.73 \pm 0.02 \mathrm{ab}$ & 1.6 & 1.08 & $1.99 \pm 0.05 \mathrm{ab}$ & 1.75 & 1.14 & $1.90 \pm 0.04 \mathrm{ab}$ & 1.77 & 1.08 \\
\hline SIP-S $-D_{2}$ & $1.34 \pm 0.11 b c$ & 2.19 & 0.61 & $1.32 \pm 0.05 c$ & 1.6 & 0.83 & $1.40 \pm 0.03 \mathrm{~d}$ & 1.75 & 0.81 & $1.20 \pm 0.02 \mathrm{de}$ & 1.77 & 0.68 \\
\hline $\mathrm{O}-\mathrm{S}_{1}-\mathrm{D}_{1}$ & $1.75 \pm 0.09 \mathrm{ab}$ & 2.19 & 0.8 & $1.84 \pm 0.03 a$ & 1.6 & 1.15 & $1.91 \pm 0.02 \mathrm{ab}$ & 1.75 & 1.1 & $1.72 \pm 0.05 b$ & 1.77 & 0.97 \\
\hline $\mathrm{O}-\mathrm{S}_{1}-\mathrm{D}_{2}$ & $1.38 \pm 0.09 \mathrm{abc}$ & 2.19 & 0.63 & $1.50 \pm 0.04 b c$ & 1.6 & 0.94 & $1.61 \pm 0.06 \mathrm{~cd}$ & 1.75 & 0.92 & $1.46 \pm 0.05 c$ & 1.77 & 0.83 \\
\hline $\mathrm{O}-\mathrm{S}_{2}-\mathrm{D}_{1}$ & $1.91 \pm 0.10 \mathrm{a}$ & 2.19 & 0.88 & $1.74 \pm 0.04 a$ & 1.6 & 1.09 & $1.97 \pm 0.06 \mathrm{ab}$ & 1.75 & 1.13 & $1.80 \pm 0.03 \mathrm{ab}$ & 1.77 & 1.02 \\
\hline $\mathrm{O}-\mathrm{S}_{2}-\mathrm{D}_{2}$ & $1.51 \pm 0.13 \mathrm{abc}$ & 2.19 & 0.69 & $1.48 \pm 0.06 c$ & 1.6 & 0.93 & $1.71 \pm 0.05 b c$ & 1.75 & 0.98 & $1.38 \pm 0.03 \mathrm{~cd}$ & 1.77 & 0.78 \\
\hline
\end{tabular}

Note: Letters in each column indicate significant differences (Tukey's test, $p<0.05$ ). ETc—culture evapotranspiration;

$\mathrm{ET}_{0}$-reference evapotranspiration.

\subsection{Moisture and Solute Distributions}

In order to study the growing media profiles, Figure 4 shows the volumetric moisture content distributions during the entire growing season. In the case of the SIP treatments, the lowest soil moisture occurred in the surface layers, and the moisture increased downwards. A maximum soil moisture was reached at the interface between the substrate and the saturated reservoir at the bottom of the container. The soil moisture profiles were different in the SIP and $\mathrm{O}$ treatments. The soil moisture was always lower in the surface layer in all of the SIP treatments than in their corresponding surface treatments, whereas at deeper layers, the soil moisture content was lower in the O treatments (Figure 4a,b). The irrigation water salinity levels influenced the water flow and the soil moisture content in the soil profile. The treatments irrigated with more saline water had a higher soil moisture. For example, the soil moisture in treatment SIP-S2 was higher than treatment SIP-S1 throughout the soil profile. The water flow was higher for the lower substrate depth (D2), so these treatments displayed a higher soil moisture than the D1 treatments (Figure 4c). Figure 5 depicts the salinity distributions in the substrate for different treatments. The salinity distribution was completely different in the SIP and 
O treatments (Figure 5a,b). The highest salinity levels were registered at the top layers in the SIPs, whereas the maximum salinity levels for the surface treatments were observed at the bottom layers. This behavior was repeated for both substrate depths, D1 and D2. As was expected, both for the SIP and surface irrigation, the S2 treatments showed higher salinity levels in the entire substrate profile than the S1 treatments. The depth of the substrate profile also affected the salinity distribution. As can be observed (Figure $5 \mathrm{c}$ ), the deeper the soil profile (treatment D1), the higher the saline levels were in the substrate.

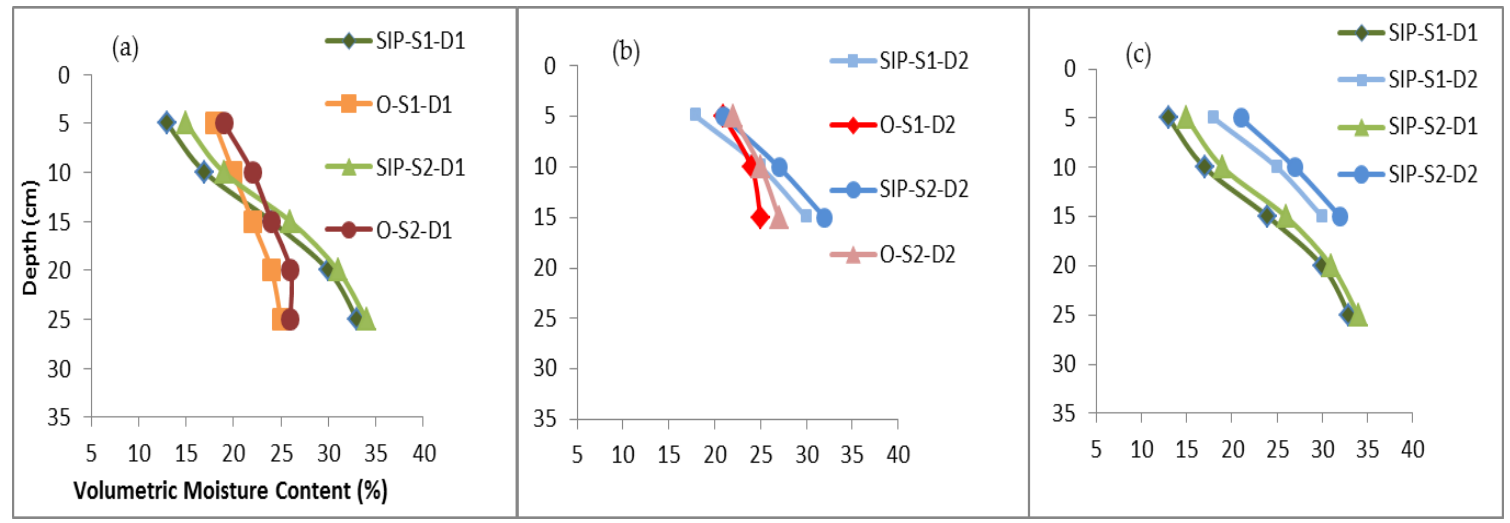

Figure 4. (a) Average volumetric moisture content (\%) at $5 \mathrm{~cm}$ intervals for SIP $\mathrm{D}_{1} \mathrm{~S}$ and their corresponding surface treatments. (b) Average volumetric moisture content (\%) at $5 \mathrm{~cm}$ intervals for SIP $D_{2} \mathrm{~S}$ and their corresponding surface treatments. (c) Average volumetric moisture content (\%) at $5 \mathrm{~cm}$ intervals for SIP $\mathrm{D}_{1}$ and SIP $\mathrm{D}_{2}$ treatments (note: 0 as the upper boundary (surface layer) of the growing medium in the pot for graphs $(\mathbf{a}-\mathbf{c})$ ).

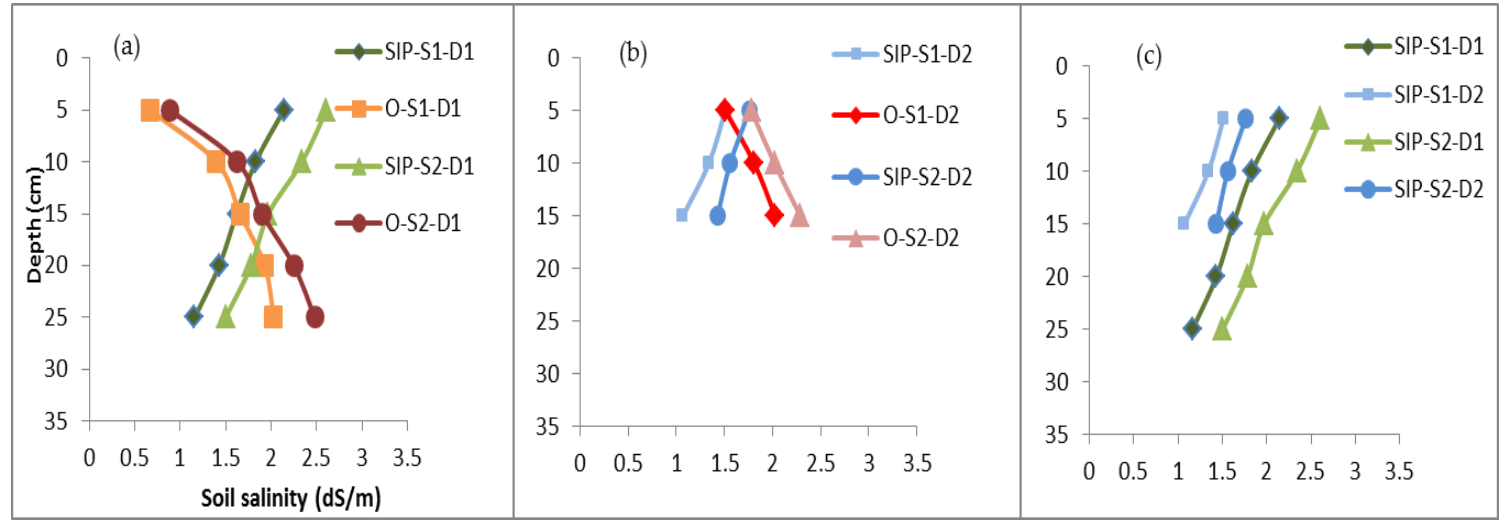

Figure 5. (a) Average soil salinity $\left(\mathrm{dS} \mathrm{m}^{-1}\right)$ at $5 \mathrm{~cm}$ intervals for $\mathrm{SIP} \mathrm{D}_{1} \mathrm{~S}$ and their corresponding surface treatments. (b) Average soil salinity $\left(\mathrm{dS} \mathrm{m}^{-1}\right)$ at $5 \mathrm{~cm}$ intervals for $\mathrm{SIP} \mathrm{D}_{2} \mathrm{~S}$ and their corresponding surface treatments. (c) Average soil salinity $\left(\mathrm{dS} \mathrm{m}^{-1}\right)$ at $5 \mathrm{~cm}$ intervals for SIP $\mathrm{D}_{1}$ and SIP $\mathrm{D}_{2}$ treatments (note: 0 as the upper boundary (surface layer) of the growing medium in the pot for graphs $(\mathbf{a}-\mathbf{c})$ ).

SIP systems must be managed precisely in order to avoid saturating the soil during the growing season. The soil surface should be monitored to prevent high salinity levels at the top layers, and, if necessary, leaching should be applied. With due attention to the abovementioned points, Figures 6 and 7 provide the average volumetric moisture contents and soil salinity levels over the course of the growing period. In all of the SIP-D1 treatments, deeper layers (fourth and fifth layers) were consistently near saturation and considerably wetter than the same layers in the O-D1 treatments. However, the SIP-D1 first and second layers continued to be drier than those of the surface irrigation (Figure $6 a, b$ ). For the SIP-D2 treatments, the third and first layers had higher and lower moisture contents, respectively, than those of the surface irrigation throughout the season (Figure 6c,d). Regarding the salinity levels, 
in the wetter layers in Figure 6, the salinity levels tended to be lower, whereas in the drier layers, they were noticeably higher (Figure 7), because the wetter the soil, the more diluted the salts are. As can be seen, the salinity levels in the root area exceeded the plant's tolerance limit in the SIP-D1 treatments (Figure 7a,b). By contrast, the SIP-D2 treatments kept the salinity level near the tolerance limit throughout the entire study period (Figure 7c,d).

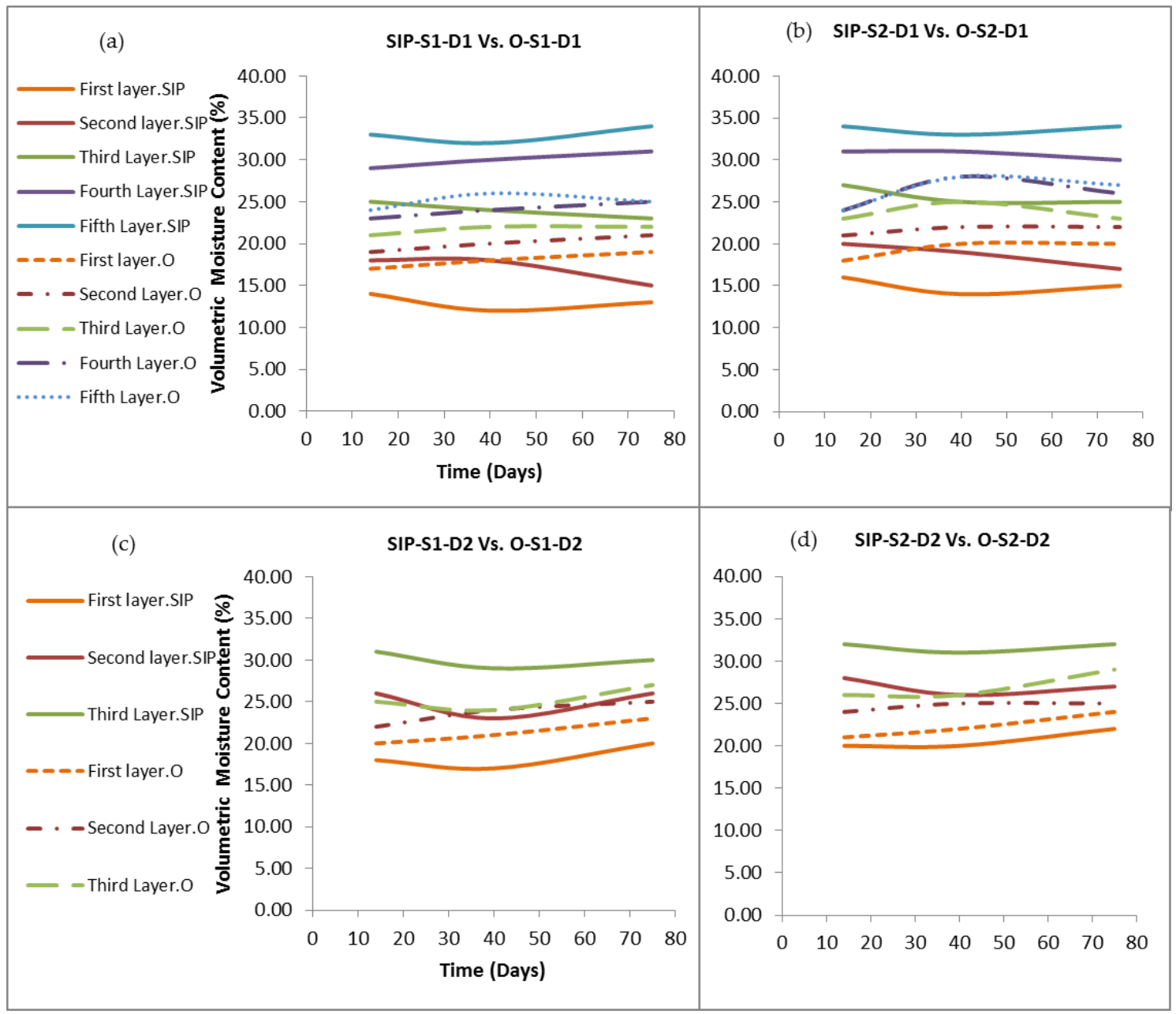

Figure 6. (a) Average volumetric moisture content (\%) for SIP-S $\mathrm{S}_{1}-\mathrm{D}_{1}$ vs. O-S $-\mathrm{S}_{1}$ over the growth period. (b) Average volumetric moisture content (\%) for SIP- $S_{2}-D_{1}$ vs. O- $S_{2}-D_{1}$ over the growth period. (c) Average volumetric moisture content (\%) for SIP-S $-\mathrm{S}_{2}$ vs. O- $\mathrm{S}_{1}-\mathrm{D}_{2}$ over the growth period. (d) Average volumetric moisture content (\%) for SIP-S $-\mathrm{D}_{2}$ vs. O- $\mathrm{S}_{2}-\mathrm{D}_{2}$ over the growth period (note: for graphs (a-d): $D_{1}$ treatments: first layer: $0-5 \mathrm{~cm}$, second layer: $5-10 \mathrm{~cm}$, third layer: $10-15 \mathrm{~cm}$, fourth layer: $15-20 \mathrm{~cm}$, fifth layer: $20-25 \mathrm{~cm}$; $\mathrm{D}_{2}$ treatments: first layer: $0-5 \mathrm{~cm}$, second layer: $5-10 \mathrm{~cm}$, third layer: $10-15 \mathrm{~cm})$. 


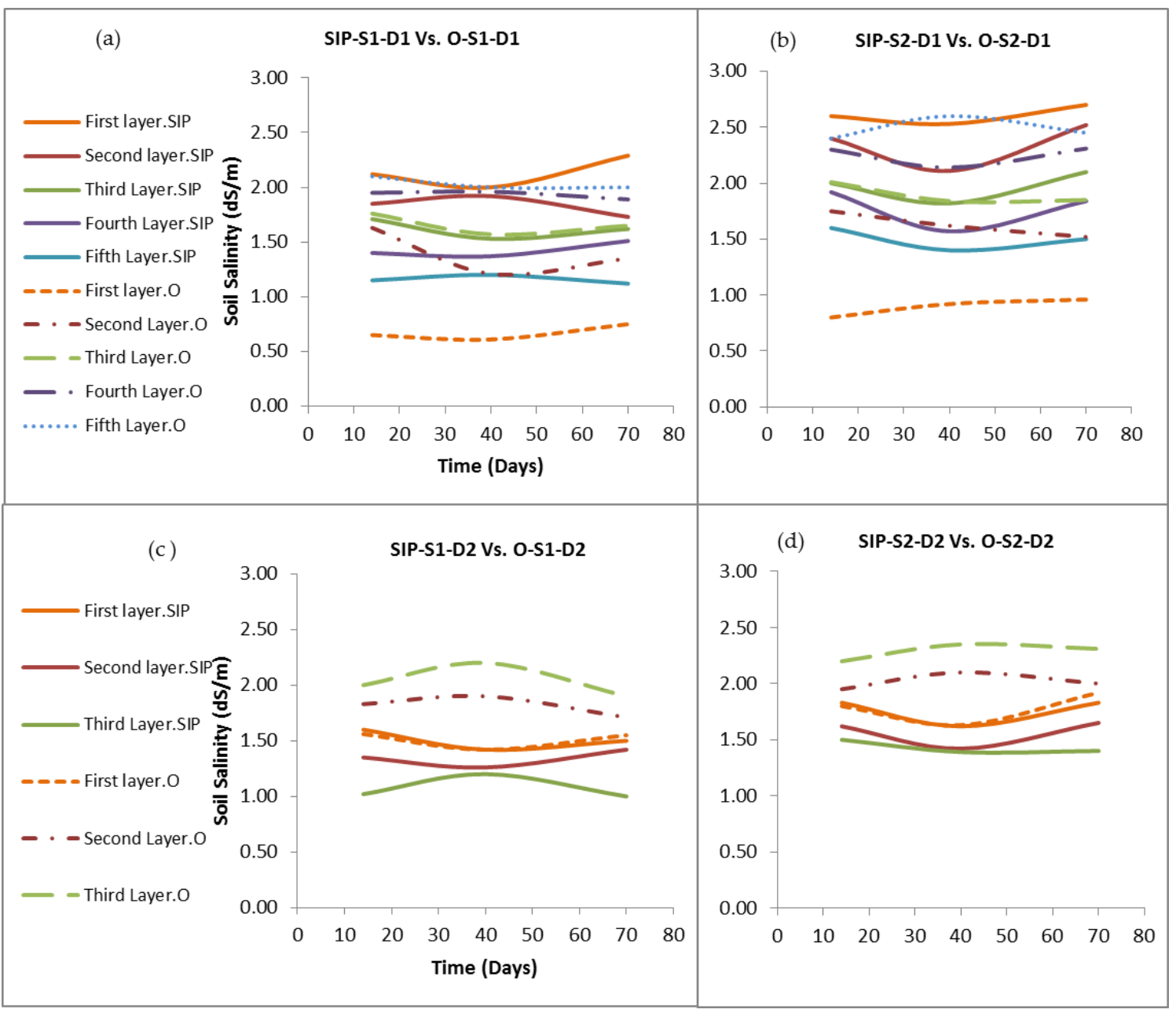

Figure 7. (a) Average growing medium salinity level for $S I P-S_{1}-D_{1}$ vs. O- $S_{1}-D_{1}$ over the growth period. (b) Average growing medium salinity level for SIP-S $-\mathrm{D}_{1}$ vs. O- $\mathrm{S}_{2}-\mathrm{D}_{1}$ over the growth period. (c) Average growing medium salinity level for SIP-S $-\mathrm{D}_{2}$ vs. O- $\mathrm{S}_{1}-\mathrm{D}_{2}$ over the growth period. (d) Average growing medium salinity level for SIP-S $-\mathrm{D}_{2}$ vs. O- $\mathrm{S}_{2}-\mathrm{D}_{2}$ over the growth period (note: For graphs (a-d): $D_{1}$ treatments: first layer: $0-5 \mathrm{~cm}$, second layer: $5-10 \mathrm{~cm}$, third layer: $10-15 \mathrm{~cm}$, fourth layer: $15-20 \mathrm{~cm}$, fifth layer: $20-25 \mathrm{~cm}$; $\mathrm{D}_{2}$ treatments: first layer: $0-5 \mathrm{~cm}$, second layer: $5-10 \mathrm{~cm}$, third layer: $10-15 \mathrm{~cm})$.

\section{Discussion}

Based on the results obtained, there was a significant difference between the SIP and surface treatments, as well as among the SIP treatments subjected to different salinities and depths. Particular emphasis should be placed on the WUE figures (Table 2), which were consistently higher in the SIPs than in their corresponding surface treatments. Lee [25] also proved that the capillary wick container systems improve water and nutrient solution efficiency in relation to conventional surface irrigation systems.

In this study, the maximum WUE was reported for treatment SIP-S1-D2 with $4.99 \mathrm{~g} \mathrm{~L}^{-1}$, while O-S2-D1 experienced the minimum WUE $\left(2.31 \mathrm{~g} \mathrm{~L}^{-1}\right)$. Nalliah [10] reported $9.33 \mathrm{~g} \mathrm{~L}^{-1}$ as the maximum WUE for the capillary negative pressure container systems, compared with $6.27 \mathrm{~g} \mathrm{~L}^{-1}$ for the hand watered pots in a study to evaluate the negative pressure capillary irrigation effect on hot pepper's quality in a greenhouse.

WUE was notably improved in the SIPs, and the reason was not only the higher plant productivity (yield), but also the lower irrigation consumption in SIP treatments compared with the surface. To determine what the main factors are for producing this result, both the plant productivities and 
total irrigation values need to be evaluated first (Table 2). As can be observed in Table 2, all of the growth parameters were significantly greater in every SIP treatment compared with its equivalent surface treatment, suggesting that the SIP treatments provided a better aeration of the root system and a higher water supply to meet the needs of the plants. This adequate supply of air and water stems from a correct combination of growing medium and irrigation techniques. Water in the SIP systems is supplied constantly through capillary action, and the substrate contains cocopeat, which has a very high water holding capacity to retain this water. Also, the incorporation of perlite increases aeration and avoids saturation in SIP. Therefore, this mixture constitutes an optimum growing media to keep water and air available over the course of the growing season [26]. In addition, SIP systems use water very efficiently, as direct evaporation from the soil surface is considerably reduced and water is not lost in drainage. In surface irrigation, on the contrary, water can be lost by both evaporation and drainage. These factors simultaneously led to a better plant yield and less water consumption in the SIP than the surface.

The results (Table 2) proved that increasing the irrigation salinity levels in SIPs (S1 vs. S2) as a container system did not significantly reduce either the growth parameters or the WUE, which coincides with Caparros et al. [27], who evaluated the water and nutrient uptake efficiency in the containerized production of lavender irrigated with saline water. This may be due to the fact that the growing medium is kept wetted enough to dilute the salts, and thus overcome the negative effects of the salinity.

Regarding the effect of the substrate depth in SIP irrigation (Table 2), all of the growth parameters were lower in D2 than in D1. In contrast, the WUE was not affected, as the total irrigation volume was accordingly lower. It is assumed that the lower depth in the SIP systems could not maintain the sufficient aeration needed for the roots, resulting in less plant productivity.

The results showed that SIP significantly improved the plant root system in terms of its weight in comparison to surface irrigation (Table 3). These findings resemble those obtained by Al-Harbi et al. [28] in their study on the effect of sub surface drip irrigation on Okra growth. This could be attributed to a better balance of water and air in the root zone using SIP, which enhanced the growth of the root system compared with surface irrigation, which tended to raise the moisture in the top layer. Another result worth mentioning is the effect of the depth of the substrate profile on root growth in the SIPs. Deeper SIP profiles yielded the most extensive and dense rooting system. This effect may be due to the larger available space in the deeper growing media, which stimulates the growth and development of the root system in the presence of optimum air and moisture distributions. Canopy weights were also significantly higher in the SIPs than in the surface irrigation (Table 3), as, in SIP, the canopy is not irrigated, which protects this part of the plant from diseases and helps it to be healthier and more well developed. Dastorani et al. [29] reported similar results on the effect of sub surface irrigation on canopy development. The fresh canopy/root ratio was higher in the O-D2 treatments, which shows that as surface irrigation uses more water than SIP, a shallow and poor root system is developed in non-limiting water conditions.

ETc was significantly greater in the SIP-D1 treatments compared with SIP-D2 at the developing, middle, and late growth stages (Table 4). According to the FAO56 guidelines, extra water in the root zone produces poor root respiration and less water and nutrition absorption, which may be the main reason for the lower ETc in the SIP-D2 treatments. Applying $15 \mathrm{~cm}$ of water in the SIP-D 2 treatments is not enough to meet the ETc requirements for the crop, which may be the main reason for the lower ETc value in the SIP $\mathrm{D}_{2}$ treatments. Taking into account the greater plant productivity and growth parameters in SIP-D1 than in SIP-D2, the importance of depth in a SIP system is revealed. It suggests a depth selection guideline for SIP users; in areas facing water scarcity, where water saving is a priority and plant productivity is a secondary objective, a lower SIP depth is recommended. On the contrary, it would be better to apply deeper SIPs for expensive ornamental or horticulture plants, whose marketability is of the utmost importance. When comparing surface and SIPs (Table 4), the ETc values were not considerably different at the beginning of the growing season, while at the late stage, 
they were significantly higher in the SIP-S1-D1 than in the O-S1-D1, and lower in the SIP-S1-D2 than in the O-S1-D2. These differences are from the abovementioned reasons; indeed, better water delivery and aeration takes place in the deepest root zone in SIP-S1-D1, and SIP-S1-D2 has poorer aeration. This behavior suggests the compatibility of using shallower depths in surface irrigation than in SIP.

The moisture content was greater in the surface treatment top layers than the SIPs (Figure 4). In SIPs, the wetter layers were located at the bottom of pots, which is logical, because of the reservoir presence at the bottom of SIP pots. All of the layers of SIP-D2 had a higher moisture content than SIP-D1 (Figure 4c), although they did not reach the saturation point. These findings highlight the need to do regular moisture monitoring of SIPs with lower depths. Another remarkable point about the same graph is the higher moisture contents in the SIP-S2 treatments compared with those of SIP-S1. Despite differing slightly, which occurred in both the D1 and D2 treatments, it can be concluded that applying saline water increases the moisture content, which is also reported in previous studies about moisture and salinity relationships [30]. FAO 56 explains that the reason for this may lie in the accumulation of salts, such as sodium, which causes the destruction of growing media's structure and plants' poor water absorption.

The highest salinity levels were observed in the top SIP layers, as well as in the deepest surface layers (Figure 5). In the surface systems, salts flowed down to deeper layers, while in SIP, salts accumulated in the drier surface layers.

It is observed that the moisture content in all of the substrate layers for the SIP treatments remained almost constant all over the growing season, with moderate fluctuations (Figure 6). In SIP, water is utilized through evaporation (which is limited in SIP) and transpiration, and the creation of a matric suction in the top layers maintains continuous capillary flow from the reservoir. SIP techniques may be easy to install and maintain, although they need precise management, depending on the meteorological data and plant absorption, so as to keep a constant flow distribution. It is necessary to maintain substrate moisture within limits, without reaching saturation conditions in the bottom layers, and the moisture must also not be lower than the allowable water depletion in the top layers throughout the growing season. It is recommended to monitor the moisture content daily when using constant reservoirs, or replace this design with SIPs without a constant reservoir (to fill reservoir at intervals), which are suitable for less water consuming plants, fine texture soils, or where there is limited access to water on daily basis.

As applying saline water using surface irrigation causes leaf burn and injures the plant canopy, the literature has advised using sub-irrigation methods to apply saline water [31,32]. Nevertheless, it should be taken into account that sub-irrigation systems may increase the salinity in the top layers, and monitoring the salinity levels while using them is unavoidable. The salinity levels in the first and second layers in the SIP-D1 treatments were always higher than in the surface irrigation throughout the entire season (Figure 7a,b). Their values exceeded the pepper salinity tolerance limit, so a mild leaching was applied at the middle of the growing season. In contrast, the third, fourth, and fifth SIP-D1 layers maintained salinity within the allowable range. Comparing SIP-D1 and D2 treatments (Figure 7a vs. Figure 7c; Figure 7b vs. Figure 7d), it should be noted that SIPs with lower depths of substrate are more appropriate for more saline irrigation waters, because the soil profile was wetter in this case and the salinity levels were maintained lower.

\section{Conclusions and Recommendations}

Fresh water scarcity will be one of the most challenging issues in agriculture, which drives irrigation specialists to promote effective and practical irrigation methods to be used in both urban and industrial greenhouses. From this point of view, the present study evaluated the performance of sub-irrigated planters-a new promising irrigation system in terms of water conservation and plant productivity. SIP irrigation was compared to surface irrigation for four treatments, comprising two different substrate depths and two different water salinities. 
The results proved that SIP outperformed surface irrigation in terms of both growth parameters and WUE. All of the SIP treatments improved WUE compared with those of the surface. In this research, the SIP-D2 treatments reached the maximum WUE values out of the SIPs, although they recorded lower yields than the SIP-D1 treatments. Therefore, it is concluded that SIP-D1 treatments are the optimum treatments for SIPs in term of improving WUE and yield simultaneously. SIP methods can be utilized when there is no access to fresh water, which was achieved in this study, as water salinity levels do not affect their performance. SIP methods require neither complicated design nor professional installation; moreover, they outperform in-ground sub-irrigation systems and standard raised beds as they are portable, which would benefit tenants.

This study suggests that SIP is a useful technique for growing pepper plants in greenhouses; however, in the continuation of this trial and in future studies, more depths and crops should be tested to find the best depth guidelines for different ranges of crops. It is also recommended that the SIP studies be conducted for two or more growing seasons so as to study their performance and effectiveness over time.

Author Contributions: Conceptualization, M.V.M., S.E.H.G., and J.R.; methodology, M.V. and S.E.H.G.; software, H.E.; validation, M.M.; formal analysis, M.V.M.; investigation, M.V.M.; resources, J.R. and M.T.L.; data curation, H.E.; writing (original draft preparation), M.V.M.; writing (review and editing), S.E.H.G., J.R., and M.T.L.; visualization, S.E.H.G.; supervision, J.R.; project administration, J.R.; funding acquisition, J.R. All authors have read and agreed to the published version of the manuscript.

Funding: This research was funded by the Spanish Ministry for Science, Innovation, and Universities program "Retos Investigación", grant number project AGL2017-85857-C2-1-R, and the APC was funded by the RIDESOST Project.

Acknowledgments: The authors would like to thank the University of Tehran for the financial support provided to Ms. Marjan Vahabi Mashhor for her research stay at the University of Almería. The set-up of the experiment was made possible thanks to the University of Almeria. We also gratefully acknowledge Dr. Juan Martinez for his technical support in climate monitoring inside the greenhouse, and Juan Lopez Herrero for practical assistance during research.

Conflicts of Interest: The authors declare no conflict of interest.

\section{References}

1. Faostat, A.C. Production. In Coping with Water Scarcity in Agriculture; Food and Agriculture Organisation (FAO): Rome, Italy, 2016.

2. Hills, D.; Brenes, M. Microirrigation of wastewater effluent using drip tape. Appl. Eng. Agric. 2001, 17, 303-308. [CrossRef]

3. Arbat, G.; PuigBargues, J.; Barragan, J.; Bonany, J.; Ramırez, F. Monitoring soil water status for micro-irrigation management versus modelling approach. Biosyst. Eng. 2008, 100, 286-296. [CrossRef]

4. Rangrizi, S.; Bahrami, H.A.; Kianirad, M.; Shojaaddini, A. Evaluating the performance of bio-composite pipes as a subsurface irrigation method in culturing panicum (Panicum antidotale). J. Soil Water Resour. Conserv. 2016, 6, 33-46.

5. Majsztrik, J.C.; Fernandez, R.T.; Fisher, P.R. Water use and treatment in container-grown specialty crop production: A review. Water Air Soil Poll. 2017, 228, 151. [CrossRef] [PubMed]

6. Gunarathna, M.H.J.P.; Sakai, K.; Nakandakari, T.; Kazuro, M.; Onodera, T.; Kaneshiro, H.; Uehara, H.; Wakasugi, K. Optimized subsurface irrigation system (OPSIS): Beyond traditional subsurface irrigation. Water 2017, 9, 599. [CrossRef]

7. Raviv, M.; Lieth, J.H. Soilless Culture: Theory and Practice, 1st ed.; Elsevier Science: Amsterdam, The Netherlands, 2008.

8. Sullivan, C.; Hallaran, T.; Sogorka, G.; Weinkle, K. An evaluation of conventional and subirrigated planters for urban agriculture: Supporting evidence. Renew. Agric. Food Syst. 2015, 30, 55-63. [CrossRef]

9. Mungai, M.M.; Wariara, K.; Gathogo, H.P.; Mwibanda, W.J.; Ochieng, A.A. Water use and plant growth of selected container grown ornamental plants under capillary wick based irrigation system and conventional irrigation system in Kenya. Int. J. Agron. Agric. Res. 2017, 11, 32-41. 
10. Nalliah, V.; Ranjan, R.S. Evaluation of a capillary-irrigation system for better yield and quality of hot pepper (Capsicum annuum). Appl. Eng. Agric. 2010, 26, 807-816. [CrossRef]

11. Eearthbox: A Pioneer Company in Container Gardening Systems. Available online: https://earthbox.com/ (accessed on 15 July 2019).

12. Palmer, D.; Grubb, A. Very Edible Gardens Company (VEG): A Permaculture Design, Education and Gardening Company. Available online: https://www.wickingbeds.com.au/ (accessed on 12 July 2019).

13. Austin, C. Wicking Bed: A New Technology for Adapting to Climate Change. Available online: http: //www.waterright.com.au/ (accessed on 25 June 2019).

14. Rhoades, J.D.; Kandiah, A.; Mashali, A.M. The Use of Saline Waters for Crop Production; Food and Agriculture Organisation (FAO): Rome, Italy, 1992.

15. Valera, D.L.; Belmonte, L.J.; Molina, F.D.; López, A. Greenhouse Agriculture in Almería: A Comprehensive Techno-Economic Analysis; Cajamar Caja Rural: Almería, Spain, 2016.

16. Maas, E.V.; Hoffman, G.J. Crop Salt Tolerance-Current Assessment. J. Irrig.Drain. 1977, 103, 115-134.

17. Navarro, J.M.; Garrido, C.; Flores, P.; Martinez, V. The effect of salinity on yield and fruit quality of pepper grown in perlite. Span. J. Agric. Res. 2010, 8, 142-150. [CrossRef]

18. De Pascale, S.; Barbieri, G. Effects of soil salinity and top removal on growth and yield of broadbean as a green vegetable. Sci. Hortic. 1997, 71, 147-165. [CrossRef]

19. Giuffrida, F.; Graziani, G.; Fogliano, V.; Scuderi, D.; Romano, D.; Leonardi, C. Effects of Nutrient and $\mathrm{NaCl}$ Salinity on Growth, Yield, Quality and Composition of Pepper Grown in Soilless Closed System. J. Plant. Nutr. 2014, 37, 1455-1474. [CrossRef]

20. Serrano, L.L.; Penella, C.; San Bautista, A.; Galarza, S.L.; Chover, A.C. Physiological changes of pepper accessions in response to salinity and water stress. Span. J. Agric. 2017, 15, 15.

21. Martínez, J.; Reca, J. Water use efficiency of surface drip irrigation versus an alternative subsurface drip irrigation method. J. Irrig. Drain. Eng. 2014, 140, 04014030. [CrossRef]

22. Cho, M.S.; Park, Y.Y.; Jun, H.J.; Chung, J.B. Growth of gerbera in mixtures of coir dust and perlite. Hortic. Environ. Biote. 2006, 47, 211-216.

23. Mobini, S.H.; Ismail, M.R.; Arouiee, H. Influence of ventilation and media on potato (Solanum tuberosum L.) tuberization and its growth characteristics. Afr. J. Biotechnol. 2009, 8, 2232-2241.

24. Knox, G.W.; Chappell, M.; Stamps, R.H.; Marble, C. Alternatives to Synthetic Herbicides for Weed Management in Container Nurseries; UGA Cooperative Extension Bulletin; University of Florida: Gainesville, FL, USA, 2012.

25. Lee, C.W.; So, I.S.; Jeong, S.W.; Huh, M.R. Application of subirrigation using capillary wick system to pot production. J. Agric. Life Sci. 2010, 44, 7-14.

26. Ilahi, W.F.F.; Ahmad, D. A study on the physical and hydraulic characteristics of cocopeat perlite mixture as a growing media in containerized plant production. Sains Malays. 2017, 46, 975-980. [CrossRef]

27. Caparros, P.G.; Llanderal, A.; Lao, M.T. Water and nutrient uptake efficiency in containerized production of fern leaf lavender irrigated with saline water. Horttech 2016, 26, 742-747. [CrossRef]

28. Al-Harbi, A.R.; Al-Omran, A.M.; El-Adgham, F.I. Effect of drip irrigation levels and emitters depth on okra (Abelmoschus esculentus) growth. J. Appl. Sci. 2008, 8, 2764-2769. [CrossRef]

29. Dastorani, M.T.; Heshmati, M.; Sadeghzadeh, M.A. Evaluation of the efficiency of surface and subsurface irrigation in dryland environments. Irrig. Drain. 2010, 59, 129-137. [CrossRef]

30. Anousheh, H.P.; Emam, Y.; Kazemeini, S.A.; Dehghany, F. Effect of irrigation water salinity on soil moisture and salinity during growing season, barley yield, and its water productivity. Iran. J. Soil. Res. 2017, 31, 155-167.

31. Patel, R.M.; Prasher, S.O.; Bonnell, R.B. Effects of watertable depth, irrigation water salinity, and fertilizer application on root zone salt buildup. Can. Agric. Eng. 2000, 42, 111-116.

32. Liaghat, A.; Amiji, M.P.; Nejad, P.M. The effect of surface and subsurface irrigation with saline water and mulch on corn yield, water productivity and solute distribution in the soil. Iran. J. Soil. Water. 2018, 32, 661-674. 